\title{
ALICE: an effective tool for groundwater-level regulation for large vine growing areas
}

\author{
Z. Boukalová ${ }^{1} \&$ Z. Křivánek ${ }^{2}$ \\ ${ }^{1}$ VODNÍ ZDROJE, a.s., Czech Republic \\ ${ }^{2}$ České Centrum pro Vèdu a Společnost, Czech Republic
}

\begin{abstract}
The aim of this paper is to describe an effective tool of groundwater-level regulation for large vine growing areas which are mostly situated in drier locations and extreme groundwater-level fluctuations may affect the quality of wine and/or may directly lead to the death of the root system. Vine growing areas are often irrigated, therefore there is a need to monitor the groundwater level which may only occur within certain height limits; a higher decline of the water column leads to drying of the vine, on the contrary, excessive irrigation may lead to rotting of the root systems and again damage to crops. The tool ALICE can also provide the maximum efficiency of water use for irrigation purposes and prevent water wastage, which will lead to significant savings for end users and the release of water for irrigation in other agricultural areas.

The paper will first introduce the pilot area in San Juan, Argentina (Valle Pedernal) and describe the technical and socio-economic activities that are planned in the pilot area under the ALICE research from May 2015 till September 2016. Definition of the alert system, analysis of system options in terms of required functions, users, operating activities, monitoring methods and resources will be discussed. The alert system ALICE that warns of extreme groundwater-level declines or rises will be based on sensing the signals from the individual measuring points - sensors located in boreholes in the area concerned, and on radio transmission of these signals to the pre-processing centre and then via the internet to a central database, accessible only to authorized persons with power of decision. Keywords: groundwater, sensors, water management, sustainable irrigation, alert system, Argentina, wine farms.
\end{abstract}




\section{Introduction: the site of San Juan}

The joint-stock company VODNÍ ZDROJE, a.s. (VZ) established a partnership with the University of San Juan in March 2011. Based on a reconnaissance of sites near San Juan (Valle del Tulúm and Valle de Pedernal) and the information about agriculture and scarcity of water resources for the irrigation of local vineyards, the corresponding technological part of the ALICE project was defined. Before the start of the ALICE project (March 2013), VZ representatives (Zuzana Boukalova and Jan Těšitel) visited the University of San Juan once more and organised a debate with the representatives of local winegrowers under the auspices of the chancellor and especially with the participation of hydrogeologist Oscar Dolling who, together with his team, became the leading contact person at the site, ensuring good communication with local final users. The discussion in San Juan resulted in a preliminary collaboration agreement with the local winegrowers association (Cámara de Bodegueros de San Juan) that showed enormous interest in the new technology and its pilot testing.

Between April and October 2014, intensive communication between VZ and the winegrowers association (further WGA) took place. Taking into account all possible aspects of collaboration as well as the needs of winegrowers and the definition of "key stakeholders", a Memorandum of Understanding between VZ and WGA was concluded under the supervision and with active participation of O. Dolling. On the basis of this memorandum, technical operations at the San Juan site can be taken up in spring 2015 for the installation of the ALICE pilot plant.

For pilot implementation in the San Juan area, the wine-growing farm of Callia was chosen. The area of interest is located in the southern part of the Pedernal valley, at an elevation ranging from 1,350 to approx. 1,450 $\mathrm{m}$ above sea level. The vineyards are situated $110 \mathrm{~km}$ southwest from Ciudad de San Juan, district of Sarmiento.

In the discussions that took place between VZ and WGA, the assignment to be carried out in Argentina was specified and an analysis was made of the system possibilities with regard to required performance, users, and necessary operations, monitoring methods, and required resources. The outputs of this analysis provide a basis for the debate with end users at the San Juan site (March 2015) as well as for a detailed plan of follow-up technical operations in situ (May 2015).

The farm of Callia covers an area of approx. 354 ha (of which 80 ha are currently productive vineyards where the Malbec variety has been grown since 2008 ) in the southern part of the Pedernal valley. In the pilot area, soils are alluvial, made of gravel of varying granulometry combined with sands, silt and clays. The proportions of the materials vary depending on the place. As a result, soils have different physical properties as well as different water retention capacity, which, in turn, makes for different growing conditions. Generally, the soils are poor showing low content of organic matter. As for climatic conditions, the highest average temperatures range between $28^{\circ}$ and $24^{\circ} \mathrm{C}$ in the period of grape ripening from January to April, while the lowest average temperatures range between $10^{\circ}$ and $4{ }^{\circ} \mathrm{C}$. The average annual precipitation - despite being higher than in the other valleys within the province - is low, reaching only a little more than $150 \mathrm{~mm}$. In 
the area of interest, water for irrigation is extracted exclusively from groundwater sources by means of wells. The static water level varies according to topography and is located at a depth of around $80 \mathrm{~m}$. Drip irrigation is used and currently two wells are in operation.
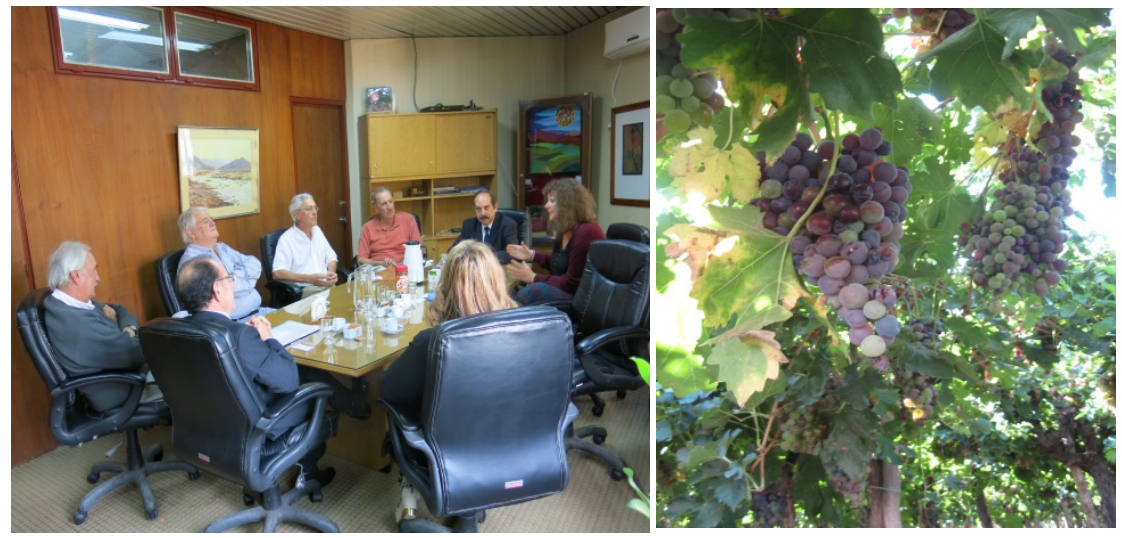

Figure 1: $\quad$ Meeting with WGA at the University of San Juan (2013).

What makes this site interesting is the use of groundwater for irrigation - the rest of the vineyards in the neighbouring Tulúm valley are irrigated with surface water from a reservoir that is distributed by a system of 3 ditches. This area is another potential site (with different irrigation conditions) to which the adjusted ALICE system could be transferred in the future.

\section{End users at the San Juan site}

At present, we have three stakeholders (end users) at the San Juan site with whom we are engaged in active communication, or we assume we will be. The set of stakeholders is merely preliminary and is going to increase if needed, probably in a snowball-like fashion, based on the situation in the model area itself. Each of the current stakeholders plays certain role in the project (the roles do not overlap yet):

- The university acts as an intermediary (very successfully)

- The winegrowers association provides the project with a broader institutional platform (that, among other things, will be used for disseminating information about the project)

The Callia bodega, as a member of the WGA, is a directly cooperating project partner whose vineyards are used for the pilot implementation. We do not communicate directly with the region/site. Instead, we use a "mutually acceptable" intermediary. As mentioned above, this role is played by the local university, which is duly motivated to perform its mediatory role properly:

- For collaboration with a foreign partner, the university gets "academic points", meaning increased state funding. 
- After the project at the San Juan site is (successfully) finished (pilot plant), the university is supposed to work as a regional partner for ensuring the market uptake of the project results.

- Its regional social status is enhanced by an example of its practical usefulness as well as the collaboration with European researchers engaged in a number of European research programmes.

The ALICE system represents a new element in the area, both material and social. From a social point of view, it creates a new situation (in this context, situation means a set of rules of conduct important for our project as well as people who either shape or follow them) that has to be "defined" by all key stakeholders to be accepted. Generally, the acceptance is the easier, the more the new situation resembles the original one. For us, as partners responsible for the implementation, this fact simply implies that we need to get to know the current situation and try not to change it too much. Instead, it is preferable to take advantage of it or imitate it whenever possible.

The major problem that can be encountered while implementing the ALICE system is the necessity to reconcile the proceedings or regulations common in the Czech Republic (and generally in Europe) with the situation at the scene. As a European company we should obviously follow the regulations valid in our country (regarding e. g. occupational safety, technology setting...). However, these regulations are embedded in our cultural background. In other countries, such as Argentina, some of them may be unacceptable for various reasons. This issue has to be taken into consideration and addressed individually based on the type of the site and final users.

Based on the experience from previous research (e. g. project STORAGE [1, 2]) a recommendation can be made not to communicate directly with the site. Instead, it is useful to establish an appropriate "interface", an intermediary (person, company, university, etc.) that will communicate for us using their knowledge of local conditions. Such an intermediary should be dependable for us and acceptable, or even better, respected in the area.

The project that we are implementing at the selected site (not only in the application of the ALICE system) is expected to have three stages:

\subsection{Preparation}

Preparation consists mainly in description of the current situation - that is existing rules (institutions), key stakeholders connected to institutions, and key stakeholders important for our project. In San Juan, the preparation stage was made in the year 2014. An indispensable part of preparation is communicating our project (our intention) to key stakeholders as well as gaining their support (eventually, it is them who should explain the activity to others). We recommend to particularly emphasis the contribution of the project to the area and its inhabitants as well as clearly specify the risks (if they are involved) and their solution. Local people must not be afraid of anything. They should trust the technology and accept the benefits brought by it. At the same time, they should be willing to operate it in the future. 


\subsection{Technical implementation itself: to be carried out in 2015-2016}

Use locally accepted proceedings/technologies and local people/employees/ enterprises as much as possible (increases the credibility of the whole campaign). As for materials, we will strive to use locally available sources only.

\subsection{Operation including monitoring of functionality: after 2016}

At this stage, we will not be at the site any more in most cases - for this reason, it is necessary to create and deliver a manual specifying by who, what and how things should be done. This manual needs to be backed up by a "social contract" (in our case, it was a MoU with the owner of the premises - the Callia vineyard). The manual should be always written in the local language (Spanish), as English will not do in most cases. In San Juan, the manual (training materials) will be created and used in 2016 based on the experience with the site and local practice. We recommend to make an evaluation after some time of how the entire project (pilot plant) works and whether the above mentioned "social contract" is respected. This is also the right time to make adjustments to it, if necessary.

\subsection{Bonus stage}

Promotion of the project aiming at its replication, involvement of students and young people in terms of education and dissemination of a "good idea", either as conference papers (for scientists as final users) or in local and regional newspapers or magazines (for the general public and other vineyard owners, in this way aiming at a potential technology transfer), using film, social media, etc.

\section{The ALICE system technology}

For the Callia farm site, the WSN (Wireless Sensor Network) system has been designed considering the fact that it is not a large site and the distances between nodes are expected to be hundreds of metres at most. According to preliminary requirements, 6 types of measuring nodes are expected to be used in total, with different connected sensors and a network coordinator/internet gateway. For radio communication within the sensor network, a free frequency band and for communication with the Internet, a mobile operator's local data network will be used. As for data flow, the network is designed in such a way that the network nodes (Node1) transmit the identification of each particular sensor + the value of the measured electric quantity, while the network coordinator Node0 interprets the measured electric quantities as a specific phenomenon and its value (with due calibration) and sends them to the data server.

The server design of the ALICE system will be parameterised according to users' specific requirements so as to enable both simple browsing through the measured data and complex time and space analyses based on them.

The technological design for sensor data collecting and processing within the ALICE system is a state-of-the-art one thanks to the use of European standards 


\section{Finca Callia}

Basic modules for Wireless Sensor Network

NODE 0

GSM interner connection WSN coordinator

NODE 1GW - ground water

(level of the groundwater)

NODE 0

\section{NODE $1 \mathrm{GW}$}

NODE 1AIR

NODE 1AIR

(temperature, humidity)

$0,05 m, 0,5 m, 1,0 m$

NODE 1SOIL

(temperature, moisture)

$-1,0 m,-0,6 m,-0,2 m$

NODE 1REP

(signal transmition/ repeater)

NODE 1REP

NODE 1PUM

NODE 1PUM

(volume of pumping water)

NODE 1 WHE

(speed and wind direction, precipitation)

Figure 2: Types of measuring nodes. 


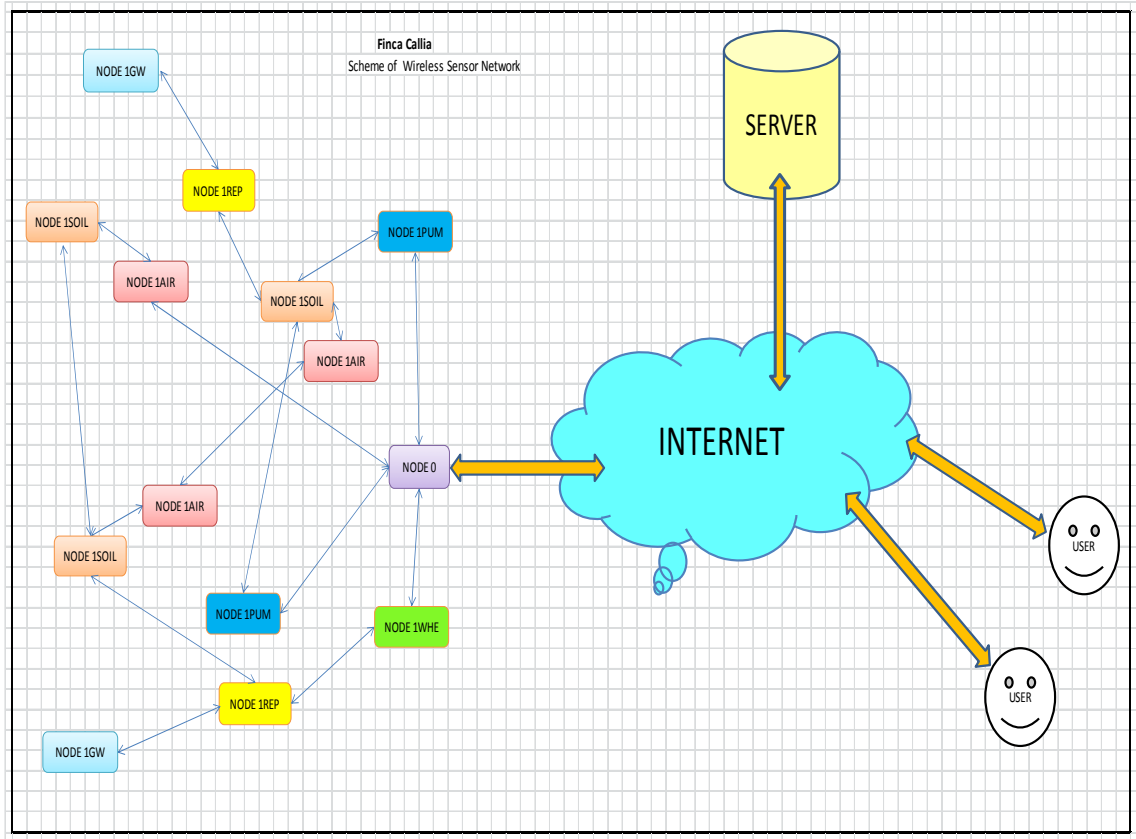

Figure 3: $\quad$ Scheme of the Wireless Sensor Network.

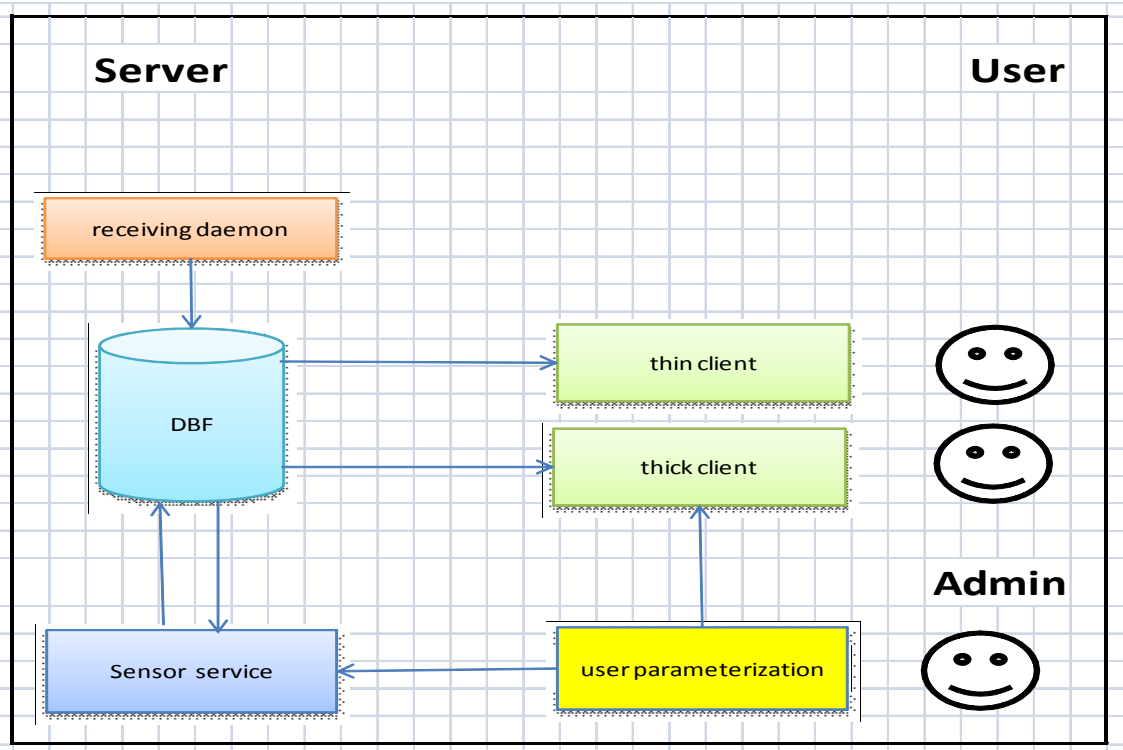

Figure 4: Scheme of the server design. 
such as INSPIRES (INfrastructure for SPatial InfoRmation in Europe). A number of early warning systems based on sensors and Wireless Sensor Networks - WSN are being developed throughout the world. Under this competition, the ALICE project is expected to define a user-friendly and cost-effective, innovative interoperable system based on a combination of sensors and a WSN - its advantage being its easy integration into the control and monitoring systems in using data collecting and processing.

\section{Conclusions}

The challenge for sustainable wine crop production is to achieve optimized yield (in quantity and quality) and farm income with a minimum of inputs (nutrients, water, but also energy, pesticides, herbicides, money), while preserving the environment.

\section{Acknowledgements}

This paper was developed thanks to the E!7616 EUREKA project ALICE, cofinanced by the Ministry of Education, Young and Sports, Czech Republic (50\%) and organizations VODNÍ ZDROJE a.s. and České Centrum pro Vědu a Společnost $(50 \%)$.

\section{References}

[1] Boukalova, Z., Těšitel, J., Sustainable solutions for cost effective rainwater harvesting in Nepal (pilot project STORAGE realized in Kathmandu valley Patan). Proc. of the River Basin Management conference, New Forest, UK, 2013.

[2] Boukalová, Z., Těšitel, J., Hrkal, Z., Kahuda, D., Artificial Infiltration as Integrated Water Resources Management Tool. Water pollution XII, Water Pollution conference, Algarve, Portugal, pp. 201-210, 2014. 